\title{
Cardiac Function in Newborns with Congenital Hypothyroidism: Association with Thyroid-Stimulating Hormone Levels
}

\author{
Taliha Öner1, Rahmi Özdemir1, Önder Doksöz1, Yılmaz Yozgat1, Cem Karadeniz1, \\ Savaş Demirpençe1, Murat Muhtar Yılmazer1, Muammer Büyükinan2, Timur Meşe1, Vedide Tavlı1 \\ ${ }^{1}$ Dr. Behçet Uz Children's Hospital, Clinic of Pediatric Cardiology, Izmir, Turkey \\ 2Konya Training and Research Hospital, Clinic of Pediatric Endocrinology, Konya, Turkey
}

\section{WHAT IS ALREADY KNOWN ON THIS TOPIC?}

Impaired left ventricular contraction and relaxation are observed in adults with hypothyroidism.

\section{WHAT THIS STUDY ADDS?}

Our results showed that congenital hypothyroidism can reduce the left ventricular systolic function and increase the risk of arrhythmia in newborn. Thyroid-stimulating hormone level is associated with heart rate and interventricular septum velocity.

\section{ABSTRACT}

Objective: The aims of this study were to demonstrate ventricular function changes in patients with congenital hypothyroidism and to investigate whether there is an association between any such changes and thyroid-stimulating hormone (TSH) levels using M-mode and Doppler electrocardiography (ECG) and tissue Doppler imaging (TDI).

Methods: Twenty-seven patients 5-30 days of age with congenital hypothyroidism who were scheduled to receive L-thyroxine treatment and 20 healthy newborns were included in this study. Twelve-lead ECG and M-mode TDI recordings of the patient and healthy groups were obtained. The patient group was divided into two subgroups according to TSH level (>100 ulU/mL or $<100 \mathrm{ulU} / \mathrm{mL}$ ), which were then compared on all parameters.

Results: Decreases were observed in the ejection fraction (EF), shortening fraction (SF), and mitral lateral annulus, mitral septal annulus, and tricuspid lateral annulus systolic velocity (Sa) on TDI, whereas left ventricular endsystolic diameter (LVESd) and corrected OT interval (OTC) dispersion were significantly increased in the patient group compared with the control group. No significant differences between the groups were found in left ventricular end-diastolic diameter (LVEDd) or heart rate. When the two patient subgroups (TSH $>100 \mathrm{ulU} / \mathrm{mL}$ and $<100 \mathrm{ulU} / \mathrm{mL}$ ) were compared, TDI septal annulus Sa wave length and heart rate were significantly lower in the $\mathrm{TSH}>100$ group.

Conclusion: Impairment in left ventricular systolic function and increased risk of arrhythmia were observed in newborn infants with congenital hypothyroidism. TSH level was associated with heart rate and interventricular septum velocity.

Key words: Newborn, congenital hypothyroidism, cardiac functions

Conflict of interest: None declared

Received: 26.02 .2015

Accepted: 30.06 .2015

Address for Correspondence

Rahmi Özdemir MD, Dr. Behçet Uz Children's Hospital, Clinic of Pediatric Cardiology, Izmir, Turkey

E-mail: rahmiozdemir35@gmail.com

OJournal of Clinical Research in Pediatric Endocrinology, Published by Galenos Publishing. 


\section{Introduction}

The incidence of congenital hypothyroidism in newborns varies between $1 / 3,500$ and $1 / 4,000$. As a result of the recent introduction of screening programs for congenital hypothyroidism also in Turkey, early diagnosis is now possible, and the number of children with cognitive delay due to hypothyroidism has decreased. Primary hypothyroidism is characterized by an increased level of blood thyroid-stimulating hormone (TSH) and decrease in free triiodothyronine $\left(\mathrm{fT}_{3}\right)$ and free thyroxine ( $\mathrm{fT}_{4}$ ) levels (1).

The effects of thyroid hormones on the cardiovascular system have been well documented. Cardiac findings in hypothyroidism include pericardial effusion, weak arterial pulse, bradycardia, hypotension, facial and peripheral edema, deepened cardiac sounds, and congestive heart failure findings such as ascites, orthopnea, and paroxysmal dyspnea $(2,3)$. Chronotropic response and normal tension of the heart muscle during diastole are due to $T_{3}$. Moreover, triiodothyronine affects the number of $B$ adrenergic receptors and their sensitivity to catecholamines (2). Cardiogenic shock, when present in a patient with hypothyroidism, demonstrates poor response to catecholamines. Severe hypothyroidism results in muscle and isovolemic relaxation, increased contraction times, and an increase in the myocardial performance index of systolic and diastolic function (4). Sinus bradycardia, low QRS voltage, prolonged OT interval, low P-wave amplitude, right branch blockage, ventricular dysrhythmia, and torsades de pointes may be seen on electrocardiography $(E C G)$ in hypothyroidism $(2,3,4,5)$. These cardiovascular effects can be reversed by $T_{4}$ treatment.

The aim of this study was to determine whether cardiac function was affected in newborns with hypothyroidism and to identify the association of any such effect with TSH levels.

\section{Methods}

Twenty-seven patients aged 5-30 days who were brought to the Dr. Behçet Uz Children's Diseases and Surgery Education and Research Hospital in Izmir, Turkey, between October 2009 and May 2010 with high TSH levels and who were scheduled to receive treatment were included in the study. Twenty age- and gender-matched healthy newborns with normal physical and cardiologic examination results served as controls. The patient group was divided into two subgroups: those with TSH levels $<100 \mathrm{ulU} / \mathrm{mL}$ and those with $\mathrm{TSH}>100 \mathrm{ulU} / \mathrm{mL}$.

Electrocardiography: Twelve-lead ECG recordings were obtained in all patients. The OT interval was taken as the period from the beginning of the $\mathrm{Q}$ wave to the end of the $T$ wave, defined as the point at which the $T$ wave converted to the TP isoelectric line. When a $U$ wave was present, the end of the T wave was defined as the lowest point between the $T$ and $U$ waves. OT dispersion was defined as the difference between the maximal and minimal OT intervals on 12-channel standard ECG. The OT intervals on ECGs were corrected using Bazett's formula [corrected QT interval $(\mathrm{QTC})=\mathrm{QT} / \sqrt{\mathrm{R}-\mathrm{R}]}$ and were expressed as QTc (6).

Echocardiography: Transthoracic two-dimensional Doppler ECG was performed using GE Vivid 3 equipment (GE Healthcare, Milwaukee, WI) and a 7S transducer. M-mode echocardiography measurements were obtained at the level of the posterior mitral valve, per the recommendations of the American Echocardiography Society (7).

Tissue Doppler imaging (TDI): Pulsed wave (PW) Doppler sampling volume and Nyquist limit in the TDI program using a $7 \mathrm{MHz}$ probe were adjusted to $2-4 \mathrm{~mm}$ and $15-20 \mathrm{~cm} / \mathrm{s}$, respectively, and the gain was adjusted to receive minimal noise and thus provide clear tissue signals. In the apical four-chamber image, the sample volume was placed at the junction of the left ventricular (LV) free wall, the mitral valve annulus, the mitral septal wall, the right ventricular (RV) free wall, and the tricuspid annulus. The recording was performed over at least five cardiac cycles, during calm periods, so that the flow was not affected by respiration. Systolic velocity (Sa) waves were recorded from the mitral lateral, mitral septal, and tricuspid lateral walls (8).

\section{Statistical Analysis}

Statistical analysis was performed using the SPSS for Windows software package (ver. 17; SPSS; Chicago, IL, USA). The Kolmogorov-Smirnov test was used to investigate the normality of distribution of the variables. Student's t-test and the Mann-Whitney U-test were used for variables with and without normal distribution, respectively, to detect any differences between the control and patient groups. A value of $p<0.05$ was taken to indicate statistical significance.

\section{Results}

Decreases were observed in the ejection fraction (EF), shortening fraction (SF), and mitral lateral annulus, mitral septal annulus, and tricuspid lateral annulus Sa on TDI (patient group: $68.56 \pm 6.04,35.96 \pm 4.59,5.12 \pm 0.81,3.85 \pm 0.61$, and $7.64 \pm 1.41$, respectively; control group: $72.63 \pm 4.77$, $39.00 \pm 3.75, \quad 5.83 \pm 1.24,4.89 \pm 0.99$, and 9.31 \pm 1.77 , respectively), whereas left ventricular end-systolic diameter (LVESd) and QTc dispersion were significantly increased in the patient group compared with the control group (patient group: $1.16 \pm 0.13$ and $0.068 \pm 0.030$, respectively; control group: $1.04 \pm 0.20$ and $0.036 \pm 0.014$, respectively). No significant differences were detected in left ventricular end-diastolic diameter (LVEDd) or heart rate between the two groups (Table 1).

When the two patient subgroups (TSH $<100 \mathrm{ulU} / \mathrm{mL}$ and $>100 \mathrm{ulU} / \mathrm{mL}$ ) were compared, the TDI septal annulus Sa wave velocity and heart rate were significantly decreased in the TSH $>100$ compared with the TSH $<100$ group $(3.55 \pm 0.52,148 \pm 16$; vs. $4.07 \pm 0.59,162 \pm 11$, respectively) (Table 2 ). 


\section{Discussion}

Impaired LV contraction and relaxation are observed in adults with hypothyroidism, commensurate with their decreased thyroid hormone levels; this condition is reversible with treatment $(9,10,11,12,13)$. The current study revealed that even during the newborn period, the systolic functions of the heart are affected, the tendency toward arrhythmia is increased due to increased QTc dispersion, and TSH levels are associated with heart rate and interventricular septal velocity in hypothyroidism.

Table 1. Comparison of the data of the total group of patients and control group (mean \pm standard deviation)

\begin{tabular}{|l|l|l|l|}
\hline Variable & Patients group & Control group & p-value \\
\hline Number of subjects & $27(37 \%$ male) & $20(55 \%$ male) & \\
\hline Age range (days) & $16.85 \pm 7.00$ & $17.00 \pm 7.13$ & $72.63 \pm 4.77$ \\
\hline EF (\%) & $68.56 \pm 6.04$ & $39.00 \pm 3.75$ & 0.01 \\
\hline SF (\%) & $35.96 \pm 4.59$ & $1.71 \pm 0.28$ & 0.02 \\
\hline LVEDd (cm) & $1.81 \pm 0.18$ & $1.04 \pm 0.20$ & NS \\
\hline LVESd (cm) & $1.16 \pm 0.13$ & $5.83 \pm 1.24$ & 0.02 \\
\hline Tissue Doppler mitral Sa (cm/sec) & $5.12 \pm 0.81$ & $4.89 \pm 0.99$ & 0.02 \\
\hline Tissue Doppler septal Sa (cm/sec) & $3.85 \pm 0.61$ & $9.31 \pm 1.77$ & 0.00 \\
\hline Tissue Doppler tricuspid Sa (cm/sec) & $7.64 \pm 1.41$ & $158 \pm 18$ & 0.00 \\
\hline Heart rate (pulse/min) & $156 \pm 14$ & $0.036 \pm 0.014$ & NS \\
\hline OTc dispersion (sec) & $0.068 \pm 0.030$ & 0.00 \\
\hline EF: ejection fraction, LVEDd: left ventricular end-diastolic diameter, LVESd: left ventricular end-systolic diameter, NS: non-significant, SF: shortening fraction &
\end{tabular}

Table 2. Comparison of the data (mean \pm SD) of the patient subgroups with thyroid-stimulating hormone greater than and less than $100 \mathrm{ulU} / \mathrm{mL}$

\begin{tabular}{|c|c|c|c|}
\hline Variable & Patients with TSH $>100 \mathrm{ulU} / \mathrm{mL}$ & Patients with TSH $<100$ ulU/mL & p-value \\
\hline Number of subjects & $11(54 \%$ male $)$ & $16(25 \%$ male $)$ & \\
\hline TSH value (ulU/mL) & $115.82 \pm 12.15$ & $47.88 \pm 23.03$ & 0.00 \\
\hline $\mathrm{fT}_{4}(\mathrm{ng} / \mathrm{dL})$ & $0.62 \pm 0.08$ & $0.89 \pm 0.09$ & 0.02 \\
\hline Age range (days) & $16.18 \pm 7.12$ & $17.31 \pm 7.11$ & NS \\
\hline $\mathrm{EF}(\%)$ & $67.27 \pm 7.15$ & $69.44 \pm 5.20$ & NS \\
\hline SF $(\%)$ & $35.00 \pm 5.60$ & $36.63 \pm 3.81$ & NS \\
\hline LVEDd (cm) & $1.78 \pm 0.12$ & $1.83 \pm 0.21$ & NS \\
\hline LVESd $(\mathrm{cm})$ & $1.15 \pm 0.13$ & $1.16 \pm 0.14$ & NS \\
\hline Tissue Doppler LV TEI & $0.54 \pm 0.12$ & $0.46 \pm 0.10$ & NS \\
\hline Tissue Doppler mitral Sa (cm/sec) & $5.00 \pm 0.77$ & $5.20 \pm 0.86$ & NS \\
\hline Tissue Doppler septal Sa (cm/sec) & $3.55 \pm 0.52$ & $4.07 \pm 0.59$ & 0.03 \\
\hline Tissue Doppler tricuspid Sa $(\mathrm{cm} / \mathrm{sec})$ & $7.64 \pm 1.20$ & $7.64 \pm 1.59$ & NS \\
\hline Heart rate (pulse/min) & $148 \pm 16$ & $162 \pm 11$ & 0.01 \\
\hline QTc dispersion (sec) & $0.076 \pm 0.031$ & $0.063 \pm 0.030$ & NS \\
\hline
\end{tabular}


When assessing LV diastolic performance, TDI is more reliable than conventional Doppler, because it is not as affected by loading conditions; furthermore, TDI measurements are more reproducible (14). Diastolic abnormalities can be detected using TDI before the onset of hemodynamic abnormalities can be identified on conventional echocardiography (15). Therefore, TDI is superior to and more sensitive than conventional echocardiography for the detection of subclinical abnormalities in the heart. TDI can be used to evaluate global and regional ventricular performance in a variety of clinical conditions. Pulsed TDI of the tricuspid annulus represents a non-invasive and reliable method of assessing RV function compared with the gold standard of magnetic resonance imaging (16). Because diastolic dysfunction starts before systolic dysfunction, tissue Doppler echocardiography may be helpful for early diagnosis of diastolic dysfunction $(17,18)$. Harada et al (19) suggested that an insufficient increase in Sa indicates an impaired response of the right ventricle to exercise in patients with tetralogy of Fallot. The Sa value obtained from the myocardial segments can be used to evaluate segmental systolic function. Regional systolic functional impairment can be defined by TDI in ischemic heart disease. A decrease in Sa rate was reported in infarct areas (20), but Sa values were decreased compared with controls also in ischemic segments without infarct. Sa values were also decreased in patients with dilated cardiomyopathy, hypertrophic cardiomyopathy, valvular heart disease, or hypertensive heart diseases. In a study of 50 neonates with congenital hypothyroidism and 35 control neonates performed by Mao et al (21) right and LV Sa values were low. Similarly, in the present study, the Sa wave velocity of the mitral lateral, mitral septal, and tricuspid lateral annuli were decreased in the group with hypothyroidism compared with the control group.

Despite recent developments resulting from improved understanding of myocardial mechanics, clinical measurement of $E F$, LV systolic volume change, $S F$, and the percentage change in systolic diameter represent the most commonly used methods of assessing ventricular function (22). In a study of 40 patients with congenital hypothyroidism and 30 normal controls, Mao et al (23) found that LV EF was decreased in the hyperthyroid group compared with the controls. Similarly, in the present study, EF and SF were decreased in the group with hypothyroidism compared with the control group.

Increased QT interval dispersion (QTd) is an electrocardiographic parameter that has been shown to be associated with malignant ventricular arrhythmias and sudden death, and QTc for heart rate has emerged as a potentially important predictor of cardiac death. Increased QTd is directly related to TSH levels in overt hypothyroidism and mean QTc was reported to be significantly increased in subclinical hypothyroidism compared with controls in several studies (24). Similarly, in the current study, OTc dispersion was increased significantly in the patient group compared with controls. However, no association was detected between TSH levels and QTc dispersion.
Sympatho-vagal regulation of heart rate is diminished in hypothyroidism. OTc dispersion is decreased significantly following treatment; however, PR and RR intervals and the duration of QRS remain unchanged (25). In a study performed on 12 patients with primary hypothyroidism using PW echocardiography, LV posterior wall and septal thickness were increased in patients with hypothyroidism, and heart rate was also reported to be increased 6 months after treatment (26). In the current study, TSH levels were associated with heart rate and interventricular septum velocity.

We are aware that our study had some limitations. In this context, difficulties in recording tissue Doppler flow rates due to tachycardia in newborn patients need to be mentioned. The study would have benefited from a larger number of subjects, and follow-up information on the patients would also have improved the study.

In conclusion, congenital hypothyroidism during the neonatal period causes impairment in the systolic functions of the heart and increases QT dispersion. Heart rate and the interventricular septal wall are affected by increased TSH levels.

\section{Authorship Contributions}

Ethics Committee Approval: A local ethical committee has not been established in our hospital at the time of the study. Therefore, the study was approved by a scientific committee comprising the hospital administration and the lecturers, Informed Consent: It was taken, Concept: Taliha Öner, Timur Meşe, Vedide Tavl, Design: Taliha Öner, Savaş Demirpençe, Data Collection or Processing: Rahmi Özdemir, Cem Karadeniz, Taliha Öner, Analysis or Interpretation: Taliha Öner, Murat Muhtar Yılmazer, Muammer Büyükinan, Literature Search: Rahmi Özdemir, Önder Doksöz, Yllmaz Yozgat, Writing: Taliha Öner, Rahmi Özdemir, Peer-review: Externally peer-reviewed, Financial Disclosure: The authors declared that this study has received no financial support.

\section{References}

1. Buyukgebiz A. Congenital hypothyroidism clinical aspects and late consequences. Pediatr Endocrinol Rev 2003;1(Suppl 2):185-190.

2. Shojaie M, Eshraghian A. Primary hypothyroidism presenting with Torsades de pointes type tachycardia: a case report. Cases J 2008;1:298.

3. Moolman JA. Thyroid hormone and the heart. Cardiovasc J S Afr 2002;13:159-163.

4. Dharmasena S, Burzyantseva O, Jayawardana S, Rupanagudy VA, Pathmanathan K. Cardiogenic shock in a patient with hypothyroid myopathy responsive only to thyroxin replacement: a case report. Cases J 2010;3:66.

5. Mathew V, Misgar RA, Ghosh S, Mukhopadhyay $P_{\text {, }}$ Roychowdhury P, Pandit K, Mukhopadhyay S, Chowdhury S. Myxedema coma: a new look into an old crisis. J Thyroid Res 2011;2011:493462.Epub 2011 Sep 15

6. Malik M, Batchvarov VN. Measurement, interpretation and clinical potential of QT dispersion. J Am Coll Cardiol 2000;36:1749-1766. 
7. Sahn DJ, DeMaria A, Kisslo J, Weyman A. Recommendations regarding quantitation in M-mode echocardiography: results of a survey of echocardiographic measurements. Circulation 1978;58:1072-1083.

8. Yu CM, Sanderson JE, Marwick TH, Oh JK. Tissue doppler imaging: a new prognosticator for cardiovascular diseases. J Am Coll Cardiol 2007;49:1903-1914. Epub 2007 Apr 30

9. Arem R, Rockey R, Kiefe C, Escalante DA, Rodriguez A. Cardiac systolic and diastolic function at rest and exercise in subclinical hypothyroidism: effect of thyroid hormone therapy. Thyroid 1996;6:397-402.

10. Biondi B, Fazio S, Palmieri EA, Carella C, Panza N, Cittadini A, Bone F, Lombardi $G$, Sacca L. Left ventricular dysfunction in patients with subclinical hypothyroidism. J Clin Endocrinol Metab 1999;84:2064-2067.

11. Monzani F, Di Bello V, Carracio N, Bertini A, Giorgi D, Giusti C, Ferrannini E. Effect of levothyroxine on cardiac function and structure in subclinical hypothyroidism: a double blind, placebo-controlled study. J Clin Endocrinol Metab 2001;86:1110-1115.

12. Tielens $E T$, Pillay $M$, Storm $C$, Berghout $A$. Changes in cardiac function at rest before and after treatment in primary hypothyroidism. Am J Cardiol 2000;85:376-380.

13. Yazici M, Gorgulu S, Sertbas Y, Erbilen E, Albayrak S, Yildiz $\mathrm{O}$, Uyan C. Effects of thyroxin therapy on cardiac function in patients with subclinical hypothyroidism: index of myocardial performance in the evaluation of left ventricular function. Int J Cardiol 2004;95:135-143.

14. Galderisi M, Nistri S, Ansalone G, Dini FL, Di Salvo G, Gallina S, Mele D, Montisci R, Sciomer S, Mondillo S, Di Bello V, Marino PN; Gruppo di Studio di Ecocardiografia della Società Italiana di Cardiologia. Pulsed tissue Doppler illustrated for residents in cardiology. G Ital Cardiol (Rome) 2007;8:92-101.

15. Aurigemma GP, Gottdiener JS, Shemanski L, Gardin J, Kitzman D. Predictive value of systolic and diastolic function for incident congestive heart failure in the elderly: the cardiovascular health study. J AmColl Cardiol 2001;37:10421048.

16. Harada K, Tamura M, Toyono M, Yasuoka K. Comparison of right ventricular Tei index by tissue Doppler imaging to that obtained by pulsed Doppler in children without heart disease. Am J Cardiol 2002;90:566-569.

17. Cullen S, Shore $D$, Redington $A$. Characterization of right ventricular diastolic performance after complete repair of tetralogy of Fallot. Restrictive physiology predicts slow postoperative recovery. Circulation 1995;91:1782-1789.

18. Gatzoulis MA, Clark AL, Cullen S, Newman CG, Redington AN. Right ventricular diastolic function 15 to 35 years after repair of tetralogy of Fallot. Restrictive physiology predicts superior exercise performance. Circulation 1995;91:1775-1781.

19. Harada K, Toyono M, Yamamoto F. Assessment of right ventricular function during exercise with quantitative Doppler tissue imaging in children late after repair of tetralogy of Fallot. J Am Soc Echocardiogr 2004;17:863-869.

20. Fukuda K, Oki T, Tabata T, luchi A, Ito S. Regional left ventricular wall motion abnormalities in myocardial infarction and mitral annular descent velocities studied with pulsed tissue Doppler imaging. J Am Soc Echocardiogr 1998;11:841-848.

21. Mao S, Wang $Y$, Jiang G, Zhao Z. Effects of levothyroxine therapy on left and right ventricular function in neonates with congenital hypothyroidism: a tissue Doppler echocardiography study. Eur J Pediatr 2007;166:1261-1265. Epub 2007 Feb 15

22. Park MK. Pediatric cardiology, noninvasive techniques, chapter 6, 2009:81-83.

23. Mao SS, Zhao ZY, Jiang GP. Left ventricular function in congenital hypothyroidism neonates before and after thyroxine substitution therapy. Zhonghua Yi Xue Za Zhi 2005;85:538-541.

24. Bakiner O, Ertorer ME, Haydardedeoglu FE, Bozkirli E, Tutuncu NB, Demirag NG. Subclinical hypothyroidism is characterized by increased QT interval dispersion among women. Med Princ Pract 2008;17:390-394. Epub 2008 Aug 6

25. Kweon KH, Park BH, Cho CG. The effects of L-thyroxine treatment on QT dispersion in primary hypothyroidism. J Korean Med Sci 2007;22:114-116

26. Virtanen VK, Saha HH, Groundstroem KW, Salmi J, Pasternack Al.Thyroid hormone substitution therapy rapidly enhances left-ventricular diastolic function in hypothyroid patients. Cardiology 2001;96:59-64. 